
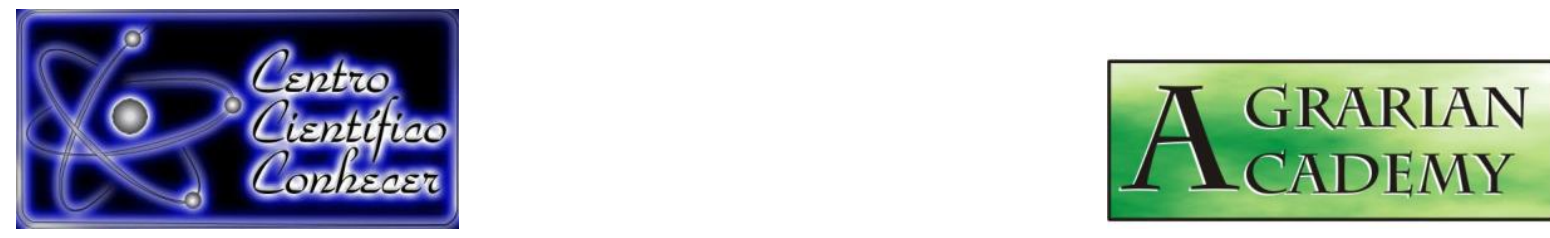

\title{
CERA DE CARNAÚBA E PRÓPOLIS NA CONSERVAÇÃO PÓS-COLHEITA DE FRUTOS DE JUAZEIRO EM CONDIÇÃO RȨFRIGERADA
}

Elma Machado Ataíde ${ }^{1}$, Tamires Eduvirgem das Dores ${ }^{2}$, Antonio Genessis Bezerra dos Santos ${ }^{2}$, Jackson Mirellys Azevêdo Souza ${ }^{3}$, Pedro Felipe Rodrigues Santos ${ }^{2}$

${ }^{1}$ Professora Doutora, Universidade Federal Rural de Pernambuco (UFRPE), Unidade

Acadêmica de Serra Talhada (UAST), Serra Talhada-PE, Brasil. Email: elma.ataide@ufrpe.br

${ }^{2}$ Graduando(a) em Agronomia, UFRPE-UAST, Serra Talhada-PE, Brasil.

${ }^{3}$ Pós-doutorando em Agronomia (Horticultura), Universidade Estadual Paulista, Botucatu, SP, Brasil

Recebido em: 30/11/2017 - Aprovado em: 15/12/2017 - Publicado em: 31/12/2017 DOI: 10.18677/Agrarian Academy 2017b29

\section{RESUMO}

O juazeiro é uma planta endêmica da caatinga e seus frutos apresentam alto valor funcional e nutricional. Contudo, em função de seu perfil climatérico, quando colhidos, apresentam rápida degradação. Face ao exposto, objetivou-se avaliar o uso de própolis e cera de carnaúba na conservação de frutos de juazeiro armazenados em condição refrigerada. $O$ trabalho foi realizado com frutos coletados da planta localizada na Unidade Acadêmica de Serra Talhada da Universidade Federal Rural de Pernambuco. Os frutos foram tratados com cera de carnaúba (100\%) e extratos alcóolico e aquoso de própolis (30\%), utilizou-se ainda frutos controle (sem tratamento). Posteriormente foram armazenados em ambiente refrigerado a $12^{\circ} \mathrm{C} \pm 2$. Avaliou-se a perda de massa dos frutos, massa média dos frutos, sólidos solúveis, acidez titulável, índice de maturação e $\mathrm{pH}$. O delineamento experimental adotado foi inteiramente casualizado, com parcelas subdivididas no tempo, sendo as parcelas constituídas por quatro tratamentos (cera de carnaúba a $100 \%$, extrato alcoólico e aquoso de própolis a $30 \%$; e testemunha) e as subparcelas pelo período de armazenamento (0,5, 10 e 15 dias), com exceção para perda de massa, onde as subparcelas foram os dias de avaliação (0 a 15 dias). A cera de carnaúba e os extratos aquoso e alcoólico de própolis promoveram menor perda de massa, maior massa fresca, maior acidez e índice de maturação semelhante aos frutos não tratados, após 15 dias. Deste modo, os tratamentos avaliados são indicados para a conservação pós-colheita de frutos de juazeiro em condição refrigerada.

PALAVRAS-CHAVE: armazenamento, características físico-químicas, Ziziphus joazeiro. 


\title{
CARNAUBA WAX AND PROPOLIS IN POST-HARVEST CONSERVATION OF JUAZEIRO FRUIT IN REFRIGERATED CONDITION
}

\begin{abstract}
Juazeiro is an endemic plant of the caatinga biome and its fruits present high functional and nutritional value. However, they are climacteric fruits and have rapid degradation after harvest. The aimed was to evaluate the use of carnauba wax and propolis in juazeiro fruit preservation stored in cooled condition. This study was conducted with fruit collected from plants located in the Academic Unit of Serra Talhada the Rural Federal University of Pernambuco. The fruits were treated with carnauba wax (100\%) and aqueous and alcoholic extracts of propolis (30\%), it is still used fruits control (no treatment). The fruits were stored in cooled condition $\left(12^{\circ} \mathrm{C} \pm\right.$ 2). Fruit weight loss, mean fruit mass, soluble solids, titratable acidity, maturation index and $\mathrm{pH}$ were evaluated. The experimental design was completely randomized with split plot. The plots consisted of four treatments (Carnauba wax $100 \%$, aqueous and alcoholic extract of propolis (30\%), and control) and subplots the storage time $(0$, 5,10 and 15 days). For the mass loss, the subplots were the evaluation days (0 to 15 days). Carnauba wax and the aqueous and alcoholic extracts of propolis promoted lower mass loss, higher fresh mass, higher acidity and maturation index similar to that of untreated fruits, after 15 days. Thus, the evaluated treatments are indicated for the post-harvest conservation of juazeiro fruits in cooled condition.
\end{abstract}

KEYWORDS: fruit quality, physico-chemical characteristics, Ziziphus joazeiro.

\section{INTRODUÇÃO}

O juazeiro, ou joazeiro (Ziziphus joazeiro Mart.), espécie da família Rhamnaceae, é endêmica do bioma Caatinga, possui relevante importância tanto econômica quanto biológica, sobretudo do ponto de vista medicinal (DANTAS et al., 2014). As plantas são de médio porte e no período de seca permanecem com folhagem verde, evidenciando a resistência a períodos de grande estiagem (LOPPES, 2010). Conforme Braga (2010), esta característica é devido ao sistema radicular profundo, e por apresentar a maior parte do ano com folhagens verdes e flores, é considerada uma frutífera importante pelos sertanejos.

O florescimento do juazeiro ocorre entre novembro e dezembro, as flores são pequenas e de coloração amarelo-esverdeada (DANTAS et al., 2014). A frutificação concentra-se entre os meses de junho e julho (CARVALHO, 2007). Frutos do tipo drupa, globosos, com coloração pardo-amarelada, medem de 1,0 a 1,5 centímetros de diâmetro, pedúnculos orlados e são comestíveis. Sementes grandes e envoltas por polpa branca, doce e mucilaginosa (DINIZ et al., 2006). Fruto com casca fina, recobre uma porção da polpa inicialmente farinácea, quando maduros são muito apreciados para o consumo na forma de fruta fresca, principalmente no período da seca. Em algumas localidades, constitui único alimento disponível para a população (CARVALHO, 2007).

Os frutos do juazeiro são constituídos, principalmente, de saponina, carboidratos, celulose e grande teor de vitamina C (DANTAS et al., 2014), configurando-se em importante fonte alimentar, tanto do ponto de vista funcional quanto nutricional. Quanto à maturação, o juá apresenta perfil climatérico (SILVA et al., 2017), ou seja, mesmo após colhidos, possuem elevada taxa de respiração e produção de etileno. Tal característica resulta em transformações nas características físicas e físico-químicas dos frutos, e podem levar à rápida perda de nutrientes, 
assim como do valor comercial. No entanto, diversas técnicas podem ser utilizadas, com vista a conservar a qualidade dos frutos depois de colhidos.

Dentre as diversas técnicas pós-colheita utilizadas para a conservação dos frutos, destaca-se a refrigeração. Todavia, este método, quando utilizado isoladamente, não evita algumas alterações físicas e químicas, de modo que se torna necessária a adoção de técnicas associadas à refrigeração (SOUZA et al., 2015). Alguma das possibilidades é o uso de recobrimento dos frutos com biofilmes comestíveis. O recobrimento de frutos com biofilmes comestíveis resulta em melhor conservação, distribuição e comercialização dos frutos, uma vez que diminuem a perda de massa dos mesmos, além de evitar danos mecânicos, físicos e microbiológicos ao produto (FALGUERA et al., 2011). Conforme Villadiego et al. (2005), há relatos do uso de ceras de abelha, parafina e carnaúba, assim como de óleos essenciais, na conservação de frutas, desde a década de 1930.

O uso de própolis e cera de carnaúba destaca-se por configurarem em materiais de composição vegetal, não poluentes e não tóxicos. A cera de carnaúba é extraída de palmeira tipicamente brasileira (Copernicia cerifera) e endêmica do semiárido nordestino, a qual é muito empregada na conservação de alimentos, resultando em menor perda de massa e maior brilho à superfície dos frutos (ARTHUSO et al., 2009). Já a própolis é constituída de substâncias resinosas, gomosas e balsâmicas, extraídas a partir de flores e exsudados de plantas pelas abelhas, as quais adicionam a estes compostos secreções salivares e cera (ARAUCO et al., 2007).

Em experimento com a lima ácida 'Tahiti', Souza et al. (2015) verificaram que os frutos armazenados em condição refrigerada e com recobrimento de cera de carnaúba apresentaram maior conteúdo de clorofila na casca após 40 dias de armazenamento, assim como melhor aceitação do suco oriundo de frutos armazenados por 20 e 40 dias, em comparação com aqueles não tratados. Enquanto Ramos et al. (2013) reportam que o recobrimento com cera de carnaúba em goiaba 'Paluma' retardou o amadurecimento e conferiu melhor aspecto e conservação aos frutos. Já Cunha et al. (2017), avaliando a conservação póscolheita de maracujá-amarelo, observaram que o extrato hidroalcólico de própolis permitiu menor perda de massa dos frutos, além de manter as características físicoquímicas no período de 16 dias. Com abacates (SANTOS et al. 2015), quando tratados com cera de carnaúba e extratos aquoso e alcóolico de própolis, obtiveram melhor resultado na conservação dos frutos com a cera de carnaúba e extrato alcoólico de própolis (30\%).

O uso de tais técnicas pode auxiliar na conservação do juá, assim como promover melhor acesso e comercialização, visto que, embora seja uma fruta nativa bastante conhecida e utilizada pela população local, a exploração baseia-se no extrativismo e poucas são as informações para o desenvolvimento tecnológico desta cultura (BRITO et al., 2005). Como mencionado, esta fruta apresenta grande potencial de consumo em virtude da composição, contudo, devido ao desconhecimento deste potencial é pouco explorada pelo homem (SILVA et al., 2011). Em vista do exposto, neste trabalho objetivou-se avaliar o uso de própolis e cera de carnaúba na manutenção da qualidade de frutos de juazeiro armazenados em condição refrigerada.

\section{MATERIAL E MÉTODOS}

O trabalho foi realizado no laboratório de química da Unidade Acadêmica de Serra Talhada da Universidade Federal Rural de Pernambuco UAST/UFRPE, 
município de Serra Talhada-PE, localizada nas coordenadas de $07^{\circ} 59^{\prime} 31^{\prime \prime}$ de latitude e 38'17'54" de longitude, com altitude de $530 \mathrm{~m}$. Para tal, foram utilizados juás coletados quando maduros, caracterizando-se pela coloração da casca amarela. Colheram-se os juás pela manhã, em plantas adultas localizadas no campus da UAST/UFRPE.

Depois de colhidos, acondicionaram-se os frutos em contentores plásticos e transportados para o laboratório onde foram lavados, sanitizados por meio de imersão em solução contendo hipoclorito de sódio a $5 \%$ e secos em temperatura ambiente. Foram aplicados os seguintes tratamentos pós-colheita: Solução de cera de carnaúba a $100 \%$, extrato alcoólico de própolis a $30 \%$ e extrato aquoso de própolis a $30 \%$, além dos frutos controle (testemunha). Após a aplicação dos tratamentos, armazenaram-se os frutos em temperatura refrigerada $12^{\circ} \mathrm{C} \pm 2$.

A resposta dos tratamentos aplicados foi avaliada mediante a determinação dos seguintes atributos: perda de massa dos frutos, sendo esta mensurada em um grupo de frutos pesados a intervalo diário, durante 15 dias e os resultados expressos em porcentagem; massa média dos frutos, aferidos com auxílio de balança digital e resultados expressos em grama; sólidos solúveis, medido com auxílio de refratômetro digital e resultados expressos em ${ }^{\circ}$ Brix; acidez titulável, expressa em porcentagem de ácido cítrico, com titulação com hidróxido de sódio $(\mathrm{NaOH})$ a 1,0 mol L $\mathrm{L}^{-1}$, em solução de $5 \mathrm{~mL}$ de suco, $95 \mathrm{~mL}$ de água destilada e $0,3 \mathrm{~mL}$ de fenolftaleína (ZENEBON et al., 2008); índice de maturação, obtido a partir da relação entre o conteúdo de sólidos solúveis e a acidez titulável; e $\mathrm{pH}$, mensurado em polpa homogeneizada com 'mixer' por meio de uso de pHmetro.

O delineamento experimental adotado foi inteiramente casualizado, com arranjo em parcelas subdivididas no tempo, sendo as parcelas constituídas pelos quatro tratamentos (cera de carnaúba a $100 \%$, extratos alcoólico e aquoso de própolis a $30 \%$ e testemunha) e as subparcelas pelo tempo de armazenamento ( 0 , 5, 10 e 15 dias), com exceção para a perda de massa, as subparcelas foram os dias de avaliação (0 a 15 dias). Utilizaram-se seis repetições com 15 frutos por parcela. Os dados obtidos foram submetidos à análise de variância e quando significativos, aplicou-se teste de regressão para as subparcelas e o teste Tukey, ao nível de 5\% de probabilidade, para os tratamentos. Para todas as análises foi utilizado o Programa Computacional Sistema para Análise de Variância - SISVAR (FERREIRA, 2011).

\section{RESULTADOS E DISCUSSÃO}

Com base nos resultados da análise de variância, verificou-se efeito significativo $(p<0,05)$ para a interação entre os 'tratamentos' $e$ os 'dias de armazenamento' para a perda de massa dos frutos. Independente do tratamento aplicado, observou-se comportamento linear crescente dos valores da perda de massa dos juás em função dos dias de armazenamento, contudo, este aumento foi menos pronunciado nos frutos com os tratamentos pós-colheita (Figura 1). Quando analisada a diferença entre os tratamentos, foi possível verificar que a perda de massa foi semelhante para todos os parâmetros até o sexto dia de armazenamento. A partir deste ponto, os frutos do controle (testemunha) apresentaram maiores valores de perda de massa, atingindo, ao final do experimento, perda de $9,87 \%$, a qual não diferiu significativamente dos tratamentos com cera de carnaúba e extrato alcóolico de própolis, sendo a menor massa obtida com o extrato aquoso de própolis $(8,20 \%)$ (Figura 1). 
Em experimento com frutos de maracujazeiro-amarelo, Cunha et al. (2017) reportam maior eficiência dos extratos hidroalcóolicos de própolis silvestre e de própolis do tipo verde em comparação com extrato aquoso de própolis, porém, todos os tratamentos avaliados promoveram menor perda de massa que os frutos não tratados. Estes autores atribuíram tal resultado à redução da pressão de vapor de água entre os frutos e, consequentemente menor taxa respiratória, uma vez que o recobrimento com biofilmes induz a redução da concentração de $\mathrm{O} 2$ e aumento de $\mathrm{CO}_{2}$ na superfície dos frutos.

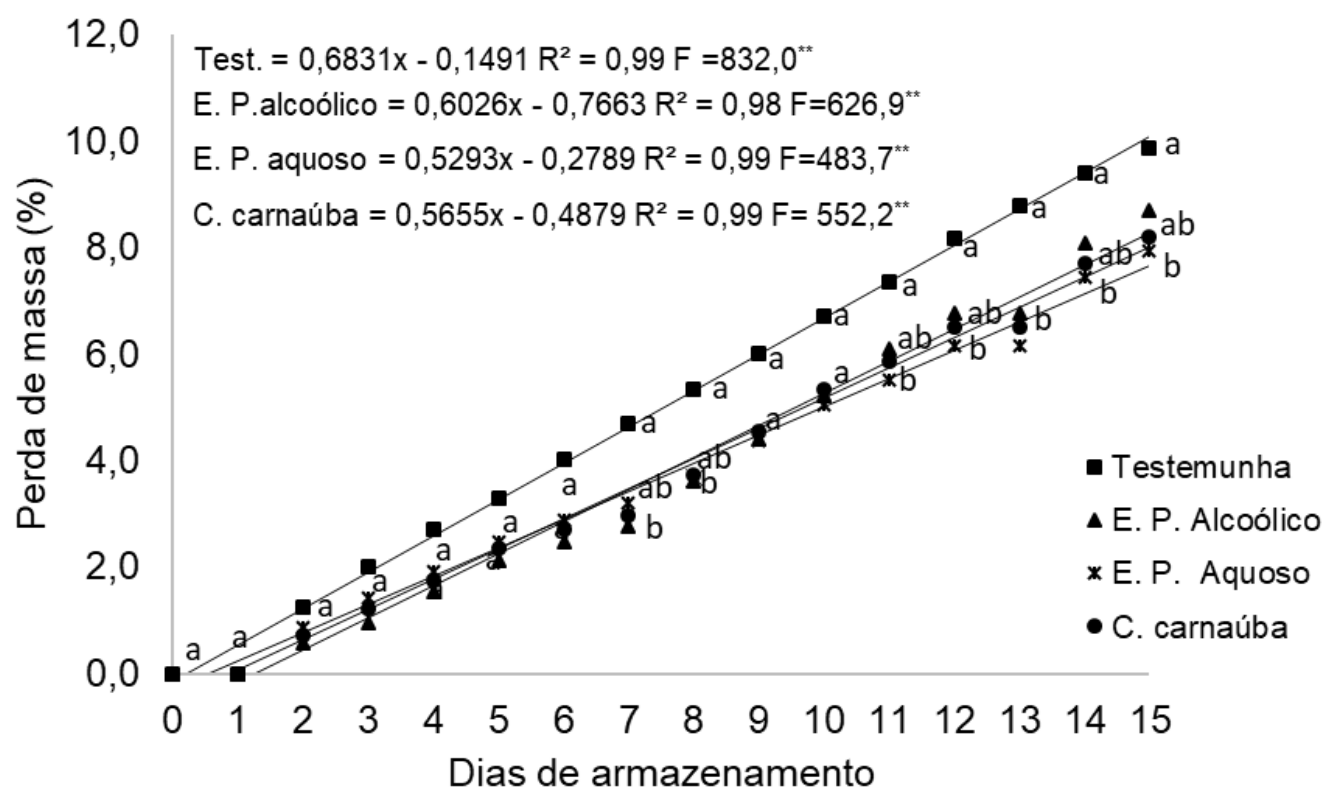

FIGURA 1. Perda de massa (\%) de frutos do juazeiro submetidos a diferentes tratamentos pós-colheita e armazenados sob refrigeração $12^{\circ} \mathrm{C}$ \pm 2 . Serra Talhada - PE. 2017.

Em relação as demais características avaliadas, com base nos resultados da análise de variância, observou-se interação significativa $(p<0,05)$ entre os 'tratamentos' e os 'dias de armazenamento' para as variáveis resposta avaliadas, com exceção do teor de sólidos solúveis, que diferiu significativamente apenas para os dias de armazenamento (Tabela 1). Esse comportamento para o teor de solúveis indicam que os valores deste atributo de qualidade não foram influenciados pela aplicação dos tratamentos.

TABELA 1. Valores do teste $F$, graus de liberdade (GL), coeficientes de variação (CV1 e 2) e médias de massa dos frutos (MF), sólidos solúveis (SS), acidez titulável (AT), índice de maturação (IM) e pH de frutos do juazeiro submetidos a diferentes tratamentos pós-colheita e armazenados sob refrigeração $12^{\circ} \mathrm{C} \pm 2$. Serra Talhada - PE. 2017.

\begin{tabular}{ccccccc}
\hline $\mathrm{FV}$ & $\mathrm{GL}$ & $\begin{array}{c}\mathrm{MF} \\
(\mathrm{g})\end{array}$ & $\begin{array}{c}\mathrm{SS} \\
\left({ }^{\circ} \text { Brix }\right)\end{array}$ & $\begin{array}{c}\mathrm{AT} \\
(\%)\end{array}$ & $\begin{array}{c}\mathrm{IM} \\
(\mathrm{SS} / \mathrm{AT})\end{array}$ & $\mathrm{pH}$ \\
\hline
\end{tabular}




\begin{tabular}{|c|c|c|c|c|c|c|}
\hline Tratamentos - A & 3 & $28,5^{* *}$ & $1,31^{\mathrm{NS}}$ & $5,3^{* *}$ & $9,7^{\star *}$ & $4,0^{*}$ \\
\hline Dias - B & 3 & $359,2^{* \star}$ & $45,5^{\star *}$ & $156,1^{\star *}$ & $34,1^{* *}$ & $12,9^{* *}$ \\
\hline$A \times B$ & 9 & $4,4^{\star *}$ & $1,4^{\mathrm{NS}}$ & $4,5^{* *}$ & $5,0^{* *}$ & $7,5^{\star *}$ \\
\hline CV $1(\%)$ & & 2,97 & 14,83 & 13,15 & 14,07 & 2,66 \\
\hline CV $2(\%)$ & & 3,52 & 9,61 & 11,34 & 13,88 & 2,61 \\
\hline Média & & 3,04 & 16,73 & 1,06 & 16,65 & 7,33 \\
\hline
\end{tabular}

Para os resultados da interação entre os 'tratamentos' e os 'dias de armazenamento', verificou-se para os valores de massa dos frutos comportamento linear decrescente para todos os tratamentos testados (Figura 2A). Porém, quando analisada a diferença entre os tratamentos em função dos dias de armazenamento, verificou-se aos 10 e 15 dias, que os tratamentos com extrato alcoólico e aquoso de própolis e a cera de carnaúba apresentaram resultados superiores quando comparados com a testemunha (Figura 2A). Esse comportamento está relacionado, diretamente, à menor perda de massa dos frutos tratados ao longo do tempo de armazenamento.

A acidez titulável dos frutos nos diferentes tratamentos avaliados aumentou de forma linear crescente em função dos dias de armazenamento (Figura 2B), sendo que na avaliação final, o tratamento testemunha apresentou a menor acidez em relação aos demais tratamentos avaliados (Figura 2B). Os ácidos orgânicos são originados da via glicolítica (quebra do açúcar) e são importantes produtos para a respiração, pois a oxidação destes compostos origina a acetil-CoA, responsável pela ativação do ciclo respiratório (LEHNINGER, 2006). Desta forma, a menor acidez dos frutos não tratados ao final do experimento é um indicativo da maior taxa de respiração, quando comparados aqueles tratados com biofilmes. Ramos et al. (2013) e Souza et al. (2015) não observaram efeito dos tratamentos com cera de carnaúba sobre a acidez titulável de goiaba e lima ácida 'Tahiti', respectivamente.
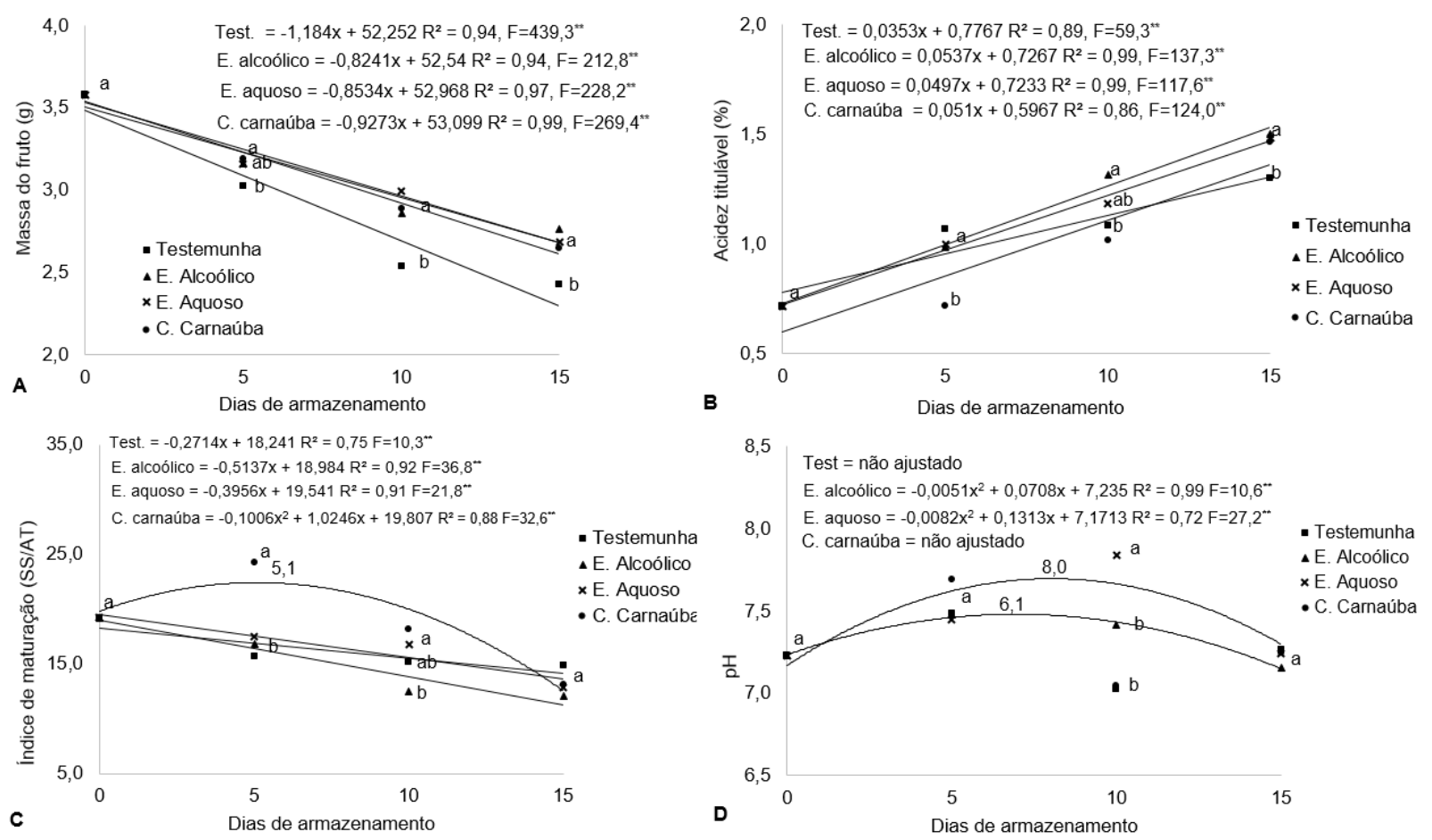

FIGURA 2. Massa do fruto (A), acidez titulável (B), índice de maturação (C) e pH (D) de frutos de juazeiro do juazeiro submetidos a diferentes tratamentos 
pós-colheita e armazenados sob refrigeração $12^{\circ} \mathrm{C} \pm 2$. Serra Talhada PE. 2017.

Já em relação ao índice de maturação, foi observado efeito linear decrescente dos resultados em função do tempo de armazenamento, com exceção para os resultados obtidos com cera de carnaúba que se ajustaram de forma quadrática em função do período de avaliação, com maior valor de índice de maturação alcançado, aos 5,1 dias de armazenamento (Figura 2C). A redução nos valores desta variável está associada à elevação das médias de acidez ao longo do período de avaliação, tendo em vista que o índice de maturação corresponde a relação entre o conteúdo de sólidos solúveis e acidez titulável dos frutos. De acordo com Chitarra e Chitarra (2005), este atributo determina o sabor da polpa dos frutos, sendo mais representativa do que a determinação isolada de sólidos solúveis ou acidez titulável, uma vez que o índice de maturação exprime a natureza doce-ácido da polpa.

Para o pH dos frutos, em função da aplicação de diferentes tratamentos e dias de armazenamento sob temperatura refrigerada, observou-se ajuste quadrático dos resultados apenas para o tratamento com extrato alcoólico e aquoso de própolis a 30\%, com maiores valores destes atributos obtidos, aos 6,1 e 8,0 dias, respectivamente (Figura 2D). Vale salientar que os resultados dos tratamentos testemunha e cera de carnaúba não se ajustaram a nenhum modelo matemático. Já em relação a comparação entre os tratamentos, foi observado diferença estatística apenas aos 10 dias de armazenamento, quando o extrato de aquoso de própolis a $30 \%$ resultou em maior $\mathrm{pH}(7,8)$ em relação aos demais (Figura $2 \mathrm{D}$ ).

Ao analisar o teor de sólidos solúveis em função dos dias de armazenamento após a aplicação dos diferentes tratamentos, verificou-se efeito linear crescente até o final do período de avaliação, com incremento médio diário nos valores deste atributo de $0,3^{\circ}$ Brix, os juás chegaram a atingir, aos 15 dias de armazenamento sob refrigeração, o teor médio de 18,8 ${ }^{\circ}$ Brix (Figura 3). O aumento do teor de sólidos solúveis pode ser explicado em virtude do aumento da perda de massa em função do tempo, a qual, em sua maior parte, se dá na forma de perda de água por transpiração, aumentando assim a concentração dos sólidos solúveis.

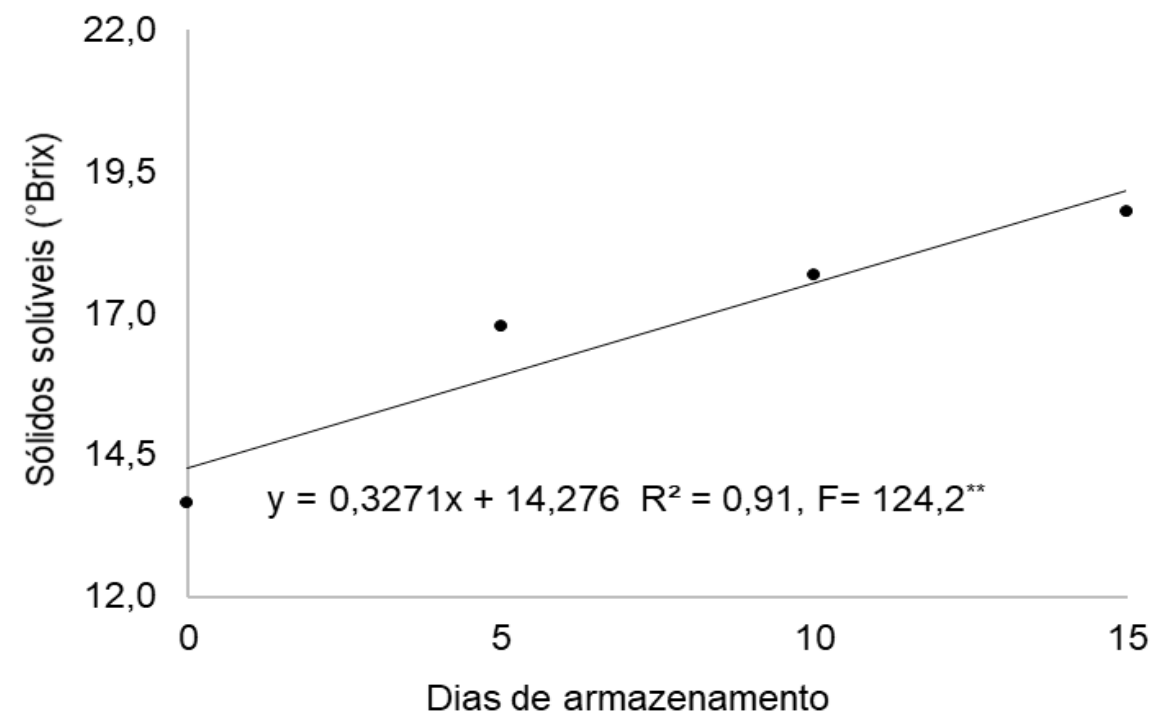

FIGURA 3. Valores de sólidos solúveis de frutos do juazeiro armazenados sob refrigeração $12^{\circ} \mathrm{C} \pm 2$. Serra Talhada - PE. 2017. 
Os maiores teores de acidez titulável e de sólidos solúveis observados nos frutos tratados, em comparação com os frutos do tratamento 'testemunha', são de grande importância para a conservação dos frutos no período pós-colheita, uma vez que, segundo Chitarra e Chitarra (2005), tais compostos são importantes produtos para a via glicolítica e ciclo respiratório, de modo que frutos com maiores valores, tendem e a ter maior período de conservação.

\section{CONCLUSÕES}

A cera de carnaúba e os extratos aquoso e alcóolico de própolis podem ser utilizados para a conservação de frutos de juazeiro em condições refrigeradas, uma vez que propiciam menor perda de massa, e consequentemente, maior massa fresca, assim como maior acidez e índice de maturação semelhante de frutos não tratados, após 15 dias.

\section{REFERÊNCIAS}

ARAUCO, L. R. R.; STÉFANI, M.; NAKAGHI, L. Efeito do extrato hidroalcoólico de própolis no desempenho e na composição leucocitária do sangue de girinos de rãtouro (Rana catesbeiana). Acta Scientiarum - Animal Science, v. 29, p.227-234, 2007. Disponível em: <http://www.redalyc.org/html/3031/303126487001/> doi: 10.4025/actascianimsci.v29i2.240

ARTHUSO, D. Z.; DONZELES, S. M. L.; PINTO, C. L. O. Cera de carnaúba: uma alternativa para conservação pós-colheita de frutas e hortaliças. In: VI Seminário de Iniciação Científica e Tecnológica, 2009, Belo Horizonte. VI Seminário de Iniciação Científica e Tecnológica. Belo Horizonte: EPAMIG, 2009.

BRAGA, R. C. JUAZEIRO (Ziziphus joazeiro) - Árvore da Caatinga com Potencial Medicinal. $2010 . \quad$ Disponível em: $<$ http://pro.casa.abril.com.br/group/cronicasdoouroverde/forum/topics/juazeiroziziphus-joazeiro>. Acesso em: 15/03/2017.

CARVALHO, P. M. R. Juazeiro Ziziphus joazeiro. Colombo, PR, Embrapa, 2007. 8p. (Comunicado Técnico, 139).

CHITARRA, M. I. F.; CHITARRA, A. B. Pós-colheita de frutas e hortaliças: fisiologia e manuseio. 2. ed. rev. e ampl. Lavras: UFLA, 2005. 785 p.

CUNHA, M. C.; PASSOS, F. R.; MENDES, F. Q.; SILVA, S. A.; ALMEIDA, W. L.; NASSER, V. G. Extrato de própolis na conservação pós-colheita de maracujáamarelo. Interciencia, v. 42, p. 320-323, 2017. Disponível em: <http://www.redalyc.org/html/339/33952810009/>.

DANTAS, F. C. P.; TAVARES, M. L. R.; TARGINO, M. S.; COSTA, A. P.; DANTAS, F. O. Ziziphus joazeiro Mart. - Rhamnaceae: características biogeoquímicas e importância no bioma Caatinga. Revista Principia, n.25, p.52-57, 2014. Disponível em: <http://dx.doi.org/10.18265/1517-03062015v2n25p51-57>. doi: 10.18265/151703062015v2n25p51-57 
DINIZ, M. F. F. M; OLIVEIRA, R. A. G.; MEDEIROS, A. C. D.; MALTA JUNIOR, A.; MOURA, M. D. Memento de plantas medicinais: as plantas como alternativa terapêutica: aspectos populares e científicos. Ed. UFPB -Universitária. 2006.

FALGUERA, V.; QUINTERO, J. P.; JIMENEZ, A.; MUÑOZ, J. A.; IBARZA, A. Edible films and coatings: structures, active functions and trends in their use. Trends in Food Science \& Technology, v. 22, n.6, p. 292-203, 2011. Disponível em: <https://doi.org/10.1016/j.tifs.2011.02.004 >. doi:10.1016/j.tifs.2011.02.004

FERREIRA, D.F. Sisvar: A computer statistical analysis system. Ciência e Agrotecnologia, Lavras, v.35, n.6, p.1039-1042, 2011.Disponível em: <http://dx.doi.org/10.1590/S1413-70542011000600001>. doi: 10.1590/S141370542011000600001

ZENEBON, O.; PASCUET, N. S.; TIGLEA, P. Métodos físico-químicos para análise de alimentos. São Paulo: Instituto Adolfo Lutz, 2008. 1020 p.

LEHNINGER, A. L. Princípios de Bioquímica. São Paulo. 4nd ed. Sarvier, 2006. p. 606- 615.

LOPPES, A. H. Índice terapêutico fitoterápico. Petrópolis: 2ed. EPUB, 2013. 328p.

RAMOS, A. R. P.; BARBOSA, A. C. A.; SILVA, E. F.; SOUZA, E. M.; Ono, E. O.; RODRIGUES, J. D. Conservação de goiaba cv. Paluma com utilização de biofilme comestível. Revista Cultivando o Saber, v. 6, p. 143-154, 2013. Disponível em: < http://hdl.handle.net/11449/140956>. Acesso em: 23/11/2017.

SANTOS, J. L. F.; ATAIDE, E. M. ; SANTOS, A. K. E.; SILVA, M. S. Recobrimentos comestíveis na conservação pós-colheita de abacate. Scientia Plena, v. 11, p. 1-7, 2015. Disponível em: <https://doi.org/10.14808/sci.plena.2015.120201>. doi: 10.14808/sci.plena.2015.120201

SILVA, J. L.; COSTA, F. B.; NASCIMENTO, A. M.; SOUSA, F. F.; SANTOS, K. P. Respiratory rate of juazeiro fruits (Ziziphus joazeiro Mart.) stored under ambient temperature. Revista Verde de Agroecologia e Desenvolvimento Sustentável, v. 12, p. 343-347, 2017. Disponível em: <http://dx.doi.org/10.18378/rvads.v12i2.4740>. doi:10.18378/rvads.v12i2.4740

SILVA, L. R.; BARRETO, D. S.; BATISTA, P. F.; ARAÚJO, F. A. R.; MORAIS, P. L. D. Caracterização de frutos de cinco acessos de juazeiro (Ziziphus joazeiro Mart.). Revista Brasileira de Produtos Agroindustriais, v.13, n.1, p.15-20, 2011. Disponível em: <http://dx.doi.org/10.15871/1517-8595/rbpa.v13n1p15-20>. doi: 10.15871/1517-8595/rbpa.v13n1p15-20

SOUZA, J. M. A.; ATAIDE, E. M. ; SILVA, M.S. Conservação pós-colheita de lima ácida 'Tahiti' com uso de ácido giberélico, cera de carnaúba e filme plástico em condição refrigerada. Revista Magistra, v. 27, p. 122-122, 2015. Disponível em < https://magistraonline.ufrb.edu.br/index.php/magistra/article/view/373/54>. Acesso em: 23/11/2017. 
VILLADIEGO, A. M. D.; SOARES, N. F. F.; ANDRADE, N. J.; PUSCHMANN, R.; MINIM, V. P. R.; CRUZ, R. Filmes e revestimentos comestíveis na conservação de produtos alimentícios. Revista Ceres, v. 53, n. 300, p. 221-244, 2005. Disponível em: <http://www.ceres.ufv.br/ojs/index.php/ceres/article/view/3040/924>. Acesso em: 23/11/2017. 